\title{
Virus Inactivation Using a High Dose of Gamma-Irradiation: A Possible Approach for Safer Vaccines Against Highly Infectious Agents
}

\section{Mohammed Alsharifi* and Shannon C. David}

Department of Molecular and Cellular Biology, Research Centre for Infectious Diseases, School of Biological Sciences, University of Adelaide, Adelaide, SA, 5005, Australia

"Corresponding author: Mohammed Alsharifi, Department of Molecular and Cellular Biology, Research Centre for Infectious Diseases, School of Biological Sciences, University of Adelaide, Adelaide, SA, 5005, Australia, Tel: +61883134632; E-mail: mohammed.alsharifi@adelaide.edu.au

Received date: May 11, 2017; Accepted date: May 22, 2017; Published date: May 26, 2017

Copyright: @2017 Alsharifi M, et al. This is an open-access article distributed under the terms of the Creative Commons Attribution License, which permits unrestricted use, distribution, and reproduction in any medium, provided the original author and source are credited.

\section{Short Communication}

Vaccination is arguably the most crucial protection strategy available against infectious agents. The World Health Organisation (WHO) estimates immunisations against the pathogens diphtheria, pertussis, tetanus, and measles avert 2-3 million deaths every year [1]. However, despite our advanced knowledge and the availability of highly effective vaccines against many diseases, several infectious agents, such as influenza A virus, continue to be a major scientific challenge. Accumulating reports of human infection with Avian influenza strains $\mathrm{H} 5 \mathrm{~N} 6, \mathrm{H} 7 \mathrm{~N} 9, \mathrm{H} 9 \mathrm{~N} 2$, and the highly pathogenic H5N1 illustrate a major public health concern. Current seasonal influenza vaccines will not protect against newly emerging pandemic strains if they acquire efficient human-human transmission and disseminate through the population. In fact, commercially available inactivated vaccines against influenza $A$ virus confer strain specific antibody-mediated protection only, and require annual reformulation to accommodate for the frequent emergence of antigenically distinct strains. In addition, the WHO recommendation for flu vaccine formulation is based on an educated-guess approach guided by WHO surveillance of recent virus activity. Our recent encounter with the pandemic pH1N1 influenza A virus in 2009 illustrates the inability of current flu vaccination strategies to control novel emerging and pandemic strains. The time required to manufacture new vaccines based on newly arising strains similarly limits the effectiveness of current strategies. These shortcomings highlight the need for a new approach to develop flu vaccines that are capable of providing protection against emerging strains.

We have previously reported the use of gamma-irradiation to inactivate Influenza A virus for vaccine purposes, and illustrated the ability of this vaccine $(\gamma$-Flu) to induce cross-protective immunity against both seasonal and pandemic virus strains, including Avian H5N1 [2]. Importantly, we demonstrated the ability of $\gamma$-Flu to induce cross-reactive cytotoxic T-cell responses [3] as well as strain-specific neutralising antibody responses [4]. We have recently published the possibility of using irradiation doses as high as $50 \mathrm{kGy}$ to inactivate influenza A virus without severely affecting vaccine immunogenicity [5]. The possible use of high irradiation dose would allow inclusion of highly pathogenic Influenza A strains in future vaccine formulations. This approach could also be used to develop a contingency plan against future pandemics, including the possibility of vaccine stockpiling as we have previously illustrated the stability of freeze-dried $\gamma$-Flu formulations [6].

It is generally accepted that inactivation of microorganisms using $\gamma$ irradiation follows physical laws, including the concept of an 'exponential law', whereby there always exists a finite probability that an organism may survive irrespective of the irradiation dose used [7].
To ensure sterility of irradiated materials, the concept of Sterility Assurance Level (SAL) has been adopted, which refers to the probability of micro-organisms surviving the irradiation process [8]. SAL is arbitrarily determined and a value of $10^{-3}$ or $10^{-6}$ (one in a thousand or a million chance of having live microorganisms in any one unit) has been widely accepted. To estimate the irradiation dose required to achieve a chosen SAL, a mathematical concept based on the decimal reduction value (the $\mathrm{D}_{10}$ value) has been used [9]. The $\mathrm{D}_{10}$ value refers to the irradiation dose required to inactivate $90 \%$ of the microbial population (i.e. a dose causing a single $\log 10$ reduction). In fact, while a SAL value of $10^{-3}$ or $10^{-6}$ has been widely accepted, exposure to higher radiation doses that exceed the critical parameter of SAL can be considered as an effective approach to further reduce the probability of any live pathogens persisting after irradiation [10]. In addition, an exposure to an irradiation dose of $50 \mathrm{kGy}$ has been largely considered as mandatory for treatment of products suspected of being contaminated with highly pathogenic agents (e.g. H5N1 Influenza, Ebola) [9]. However, an exposure to high irradiation dose may be associated with extensive damage to antigenic structure, consequently affecting vaccine efficacy.

It is important to emphasize that the "radiation sensitivity" of a pathogen is mainly related to damage to nucleic acid structure (for example, single- or double-strand breaks, cross-linkages, and other nucleotide damage). In addition, gamma-irradiation has been shown to be associated with protein damage [11], including fragmentation due to breakage of covalent bonds within the polypeptide chain [12]. This is illustrated by excessive damage to Murine Norovirus 1 (MNV-1) capsid protein VP1 following irradiation with increased doses of gamma-rays at room temperature [13]. Importantly, modulating irradiation conditions could help control the extent of the structural damage. Our recently published data illustrate that irradiation of influenza A virus on dry ice is associated with limited structural damage compared to irradiation at room temperature [5]. Our data show that influenza A virus irradiated at room temperature suffered significantly greater loss of surface protein functionality and increased damage to virion integrity, leading to reduced vaccine efficacy. In contrast, irradiation on dry-ice aided preservation of virion integrity and allowed for significant maintenance of antigenic epitopes. Thus, our data illustrated the high immunogenicity of materials irradiated on dry-ice, despite the exposure to $50 \mathrm{kGy}$. Achieving vaccine sterility without damaging antigenic epitopes is essential for future development of highly effective vaccines. Interestingly, irradiation of frozen materials (at $-80^{\circ} \mathrm{C}$ ) has also been reported previously for inactivation of Venezuelan Equine Encephalitis Virus (VEEV) and Eastern Equine Encephalitis Virus (EEEV) for vaccine purposes using high doses of irradiation. VEEV irradiated with $50 \mathrm{kGy}$ was reported to induce protection against subcutaneous and aerosol 
Citation: Alsharifi M, David SC (2017) Virus Inactivation Using a High Dose of Gamma-Irradiation: A Possible Approach for Safer Vaccines Against Highly Infectious Agents. J Vaccines Vaccin 8: 360. doi:10.4172/2157-7560.1000360

Page 2 of 2

challenge with live virus in mice [14]. In addition, EEEV irradiated with $100 \mathrm{kGy}$ was shown to induce both neutralising antibody responses and protection against aerosol challenge [15]. These studies support our early proposal regarding the suitability of gammairradiation to inactivate highly infectious agents for vaccine purposes [7]. A combination of high irradiation dose and a controlled irradiation temperature appeared to be sufficient to minimise structural damage, and consequently ensures vaccine safety and efficacy. This technique may be applied to pathogens against which vaccine design has been inherently complicated. Recent reports of phase I human clinical trials of an attenuated HIV vaccine doublytreated with gamma-irradiation (30 kGy) and chemical inactivation (Trial Registration: Clinical Trials NCT01546818) illustrate the effectiveness of gamma-irradiation as a clinically relevant vaccine inactivation method [16].

Overall, gamma-irradiation represents a very promising approach for development of highly effective vaccines. The high immunogenicity of materials irradiated with $50 \mathrm{kGy}$ considerably expands the list of pathogens suitable for irradiation treatment for vaccine purposes. In addition, irradiation may be used to inactivate existing live attenuated vaccines to enhance safety and to allow for administration of an increased antigen dose without compromising efficacy.

\section{References}

1. World Health Organisation (2017) Immunization Coverage. WHO.

2. Alsharifi M, Furuya Y, Bowden TR, Lobigs M, Koskinen A, et al. (2009) Intranasal flu vaccine protective against seasonal and $\mathrm{H} 5 \mathrm{~N} 1$ avian influenza infections. PLoS One 4: e5336.

3. Furuya Y, Chan J, Regner M, Lobigs M, Koskinen A, et al. (2010) Cytotoxic $\mathrm{T}$ cells are the predominant players providing cross-protective immunity induced by \{gamma\}-irradiated influenza A viruses. J Virol 84: 4212-4221.

4. Chan J, Babb R, David SC, McColl SR, Alsharif M (2016) VaccineInduced Antibody Responses Prevent the Induction of Interferon Type I Responses Upon a Homotypic Live Virus Challenge. Scand J Immunol 83: 165-173.

5. David SC, Lau J, Singleton EV, Babb R, Davies J, et al. (2017) The effect of gamma-irradiation conditions on the immunogenicity of wholeinactivated Influenza A virus vaccine. Vaccine 35: 1071-1079.
6. Furuya Y, Regner M, Lobigs M, Koskinen A, Mullbacher A, et al. (2010) Effect of inactivation method on the cross-protective immunity induced by whole 'killed' influenza A viruses and commercial vaccine preparations. Journal of General Virology 91: 1450-1460.

7. Alsharifi M, Mullbacher A (2010) The gamma-irradiated influenza vaccine and the prospect of producing safe vaccines in general. Immunol Cell Biol 88: 103-104.

8. International Atomic Energy Agency (1990) Guidelines for Industrial Radiation Sterilization of Disposable Medical Products (Cobalt-60 Gamma Irradiation), in The Technical Reports Series. International Atomic Energy Agency: Vienna 539: 39.

9. Department of Agriculture (2014) Gamma Irradiation as a Treatment to Address Pathogens of Animal Biosecurity Concern - Final Policy Review, CC BY 3.0.

10. Hasanain F, Guenther K, Mullett WM, Craven E (2014) Gamma sterilization of pharmaceuticals-a review of the irradiation of excipients, active pharmaceutical ingredients, and final drug product formulations. PDA J Pharm Sci Technol 68: 113-137.

11. Kempner ES (2001) Effects of high-energy electrons and gamma rays directly on protein molecules. J Pharm Sci 90: 1637-1646.

12. Lee Y, Song KB (2002) Effect of gamma-irradiation on the molecular properties of myoglobin. J Biochem Mol Biol 35: 590-594.

13. Feng K, Divers E, Ma Y, Li J (2011) Inactivation of a human norovirus surrogate, human norovirus virus-like particles, and vesicular stomatitis virus by gamma irradiation. Appl Environ Microbiol 77: 3507-3017.

14. Martin SS, Bakken RR, Lind CM, Garcia P, Jenkins E, et al. (2010) Comparison of the immunological responses and efficacy of gammairradiated V3526 vaccine formulations against subcutaneous and aerosol challenge with Venezuelan equine encephalitis virus subtype IAB. Vaccine 28: 1031-1040.

15. Honnold SP, Bakken RR, Fisher D, Lind CM, Cohen JW, et al. (2014) Second generation inactivated eastern equine encephalitis virus vaccine candidates protect mice against a lethal aerosol challenge. PLoS One 9: e104708.

16. Choi E, Michalski CJ, Choo SH, Kim GN, Banasikowska E, et al. (2016) First Phase I human clinical trial of a killed whole-HIV-1 vaccine: demonstration of its safety and enhancement of anti-HIV antibody responses. Retrovirology 13: 82 . 